\title{
A comparative study of argon laser and krypton laser in the treatment of diabetic optic disc neovascularisation
}

\author{
W. E. SCHULENBURG, A. M. HAMILTON, AND R. K. BLACH \\ From the Institute of Ophthalmology and Moorfields Eye Hospital, City Road, London
}

SUMMARY A comparative study of the relative efficacy of the krypton and argon lasers in the treatment of disc new vessels in diabetic retinopathy was made. Resolution of the disc new vessels was achieved in both instances. There were clinical differences in the use and effects of the 2 lasers.

Panretinal photocoagulation is an established method of treatment of proliferative diabetic retinopathy in eyes with optic disc neovascularisation (Cheng et al., 1976). However, marked shrinkage of visual fields often follows xenon-arc treatment because the burns frequently affect the nerve fibre layer of the retina (Hamilton et al., 1976). The ruby laser, although it does not give such field constriction, proves to be successful in only $21 \%$ of eyes (Aiello et al., 1968). The argon laser photocoagulator was developed by L'Esperance (1968) so as to render precise control of the beam diameter, exposure time, and power. It is now widely used in the management of proliferative diabetic retinopathy and is particularly effective where neovascularisation involves the optic disc (Diabetic Retinopathy Study Research Group, 1976).

The krypton laser photocoagulator differs from the argon laser photocoagulator in that it emits a red beam with a wavelength of $647 \cdot 1 \mathrm{~nm}$ as opposed to a blue-green beam with the main wavelengths of 488.0 and $514.5 \mathrm{~nm}$ with the argon laser. Therefore, theoretically little energy from the krypton laser is absorbed by haemoglobin, which precludes direct coagulation of retinal blood vessels (François and Cambie, 1977) (Fig. 1).

The purpose of this study is to compare the effectiveness of argon laser photocoagulation with krypton laser photocoagulation in the treatment of diabetic optic disc neovascularisation by panretinal photocoagulation.

\section{Patients and methods}

Patients seen in the diabetic clinic with neovascularisation involving the optic disc, a vision of $6 / 9$ or

Address for reprints: Dr W. E. Schulenburg, Moorfields Eye Hospital, City Road, London ECIV 2PD

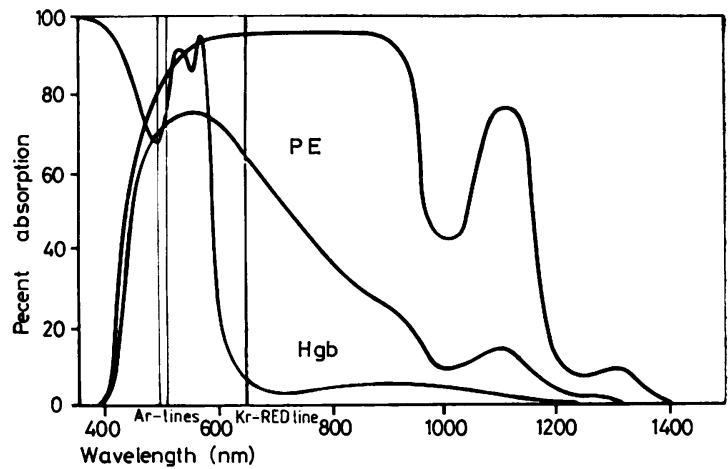

Fig. 1 Ocular transmission curve, absorption curve of melanin in the pigment epithelium (PE) and the choroid, and absorption curve of haemoglobin ( $\mathrm{Hgb})$

better, and who could attend for review were randomly selected for treatment by either the argon laser or the krypton laser. Patients were excluded from the study when treatment could not be completed in 1 treatment session.

The Coherent 800 argon laser and the Lasertek krypton laser were used for treatment. The selection of treatment was in accordance with a preexisting randomised list. The new blood vessels on the optic disc were graded according to the Hammersmith classification of disc neovascularisation (Kohner et al., 1971). The method of treatment was by the technique of pan-photocoagulation, and this was completed in 1 session, a minimum of 2000 burns being applied (Hamilton et al., 1976). The $200-\mu \mathrm{m}$ spot size was used around the posterior pole and the $500-\mu \mathrm{m}$ spot size further out in the periphery up to and beyond the equator. With both instruments the timing was set at 0.2 second and the intensity was adjusted until a 'light burn' was achieved. 
Table 1 Results

\begin{tabular}{|c|c|c|c|c|c|c|c|c|c|}
\hline & \multicolumn{2}{|l|}{ Visual acuity } & \multirow[b]{2}{*}{$\begin{array}{l}\text { Number } \\
\text { of burns }\end{array}$} & \multicolumn{3}{|c|}{ Effect of treatment at 2 days } & \multirow[b]{2}{*}{$\begin{array}{l}\text { Initial } \\
\text { grade of } \\
\text { vessels }\end{array}$} & \multirow[b]{2}{*}{$\begin{array}{l}\text { Grade at } \\
10 \text { weeks }\end{array}$} & \multirow[b]{2}{*}{ Complications } \\
\hline & Pretreatment & $\begin{array}{l}10 / 52 \\
\text { Post-treatment }\end{array}$ & & Myopia & Shallow $A C$ & $\begin{array}{l}\text { Annular } \\
\text { choroidal } \\
\text { detachment }\end{array}$ & & & \\
\hline \multicolumn{10}{|c|}{ Argon } \\
\hline 1 & $6 / 9$ & $6 / 9$ & 2327 & - & - & - & 3 & 1 & \\
\hline 2 & $6 / 9$ & $6 / 18$ & 2012 & - & - & - & 2 & 2 & Vitreous haemorrhage \\
\hline 3 & $6 / 9$ & $6 / 9$ & 2028 & + & + & + & 3 & 0 & \\
\hline 4 & $6 / 9$ & $6 / 12$ & 2052 & - & - & - & 5 & 3 & Vitreous haemorrhage \\
\hline 5 & $6 / 5$ & $6 / 5$ & 2024 & - & - & - & 2 & 0 & \\
\hline 6 & $6 / 5$ & $6 / 5$ & 2004 & - & - & - & 4 & 0 & \\
\hline \multicolumn{10}{|c|}{ Krypton } \\
\hline 1 & $6 / 9$ & $6 / 9$ & 2005 & + & + & + & 5 & 0 & \\
\hline 2 & $6 / 6$ & $6 / 6$ & 2000 & + & + & + & 2 & 0 & \\
\hline 3 & $6 / 9$ & $6 / 9$ & 2013 & - & - & - & 3 & 2 & \\
\hline 4 & $6 / 9$ & $6 / 18$ & 2037 & + & + & + & 5 & 3 & Vitreous haemorrhage \\
\hline 5 & $6 / 9$ & $6 / 9$ & 2015 & + & + & + & 3 & 0 & \\
\hline 6 & $6 / 5$ & $6 / 5$ & 2003 & - & - & - & 5 & 0 & \\
\hline
\end{tabular}

Patients were evaluated initially, and at 1,3 , and 10 weeks. Corrected visual acuity and visual fields were tested, fluorescein angiography was carried out, and colour photographs were taken. In addition they were also examined on the second day after treatment for macular oedema, annular choroidal detachment, and anterior chamber depth.

\section{Results}

Twelve eyes in 8 patients qualified for the study. Six eyes were treated by the argon laser and 6 by the krypton laser.

\section{VISUAL ACUITY}

The majority of eyes retained their pretreatment visual acuities at 10 weeks after treatment. Vision deteriorated in only 3 eyes during the study owing to vitreous haemorrhages developing from persistent new vessels on the optic disc (Table 1).

\section{ANTERIOR CHAMBER DEPTH}

Examination on the second postoperative day showed shallow anterior chambers in 4 eyes treated by the krypton laser and in 1 eye treated by the argon laser, and all 5 eyes had an associated annular choroidal detachment. In none of the eyes with shallow anterior chamber and annular choroidal detachment was there any evidence of raised intraocular pressure. All 5 eyes showed a deteriora- tion of their visual acuities and had myopia ranging from -0.5 to -1.0 dioptres. Return to the previous refraction occurred 1 week after treatment. In no patients was macular oedema observed after treatment.

VISUAL FIELDS

Perimetry was done on the Goldmann perimeter with 3 different white targets.

$\begin{array}{llll}\text { Objective } & \text { V } & \text { I } & \text { I } \\ \text { Intensity } & 4 & 4 & 2\end{array}$

The visual fields remained unchanged for $V / 4$ throughout the study. There was an average centripetal shrinkage of 7 degrees for $I / 4$ in both groups 1 week after treatment and 10 degrees for $I / 2$. Ten weeks after treatment both groups showed some recovery of their visual fields, though it was more pronounced in the krypton-treated group with an

Table 2 Average centripetal field shrinkage 1 week and 10 weeks after treatment

\begin{tabular}{lllll}
\hline & & $V / 4$ & $I / 4$ & $I / 2$ \\
\hline Argon & 1 week & $0^{\circ}$ & $7^{\circ}$ & $10^{\circ}$ \\
& 10 weeks & $0^{\circ}$ & $5^{\circ}$ & $9^{\circ}$ \\
\multirow{3}{*}{ Krypton } & 1 week & $0^{\circ}$ & $7^{\circ}$ & $10^{\circ}$ \\
& 10 weeks & $0^{\circ}$ & $3^{\circ}$ & $7^{\circ}$ \\
\hline
\end{tabular}




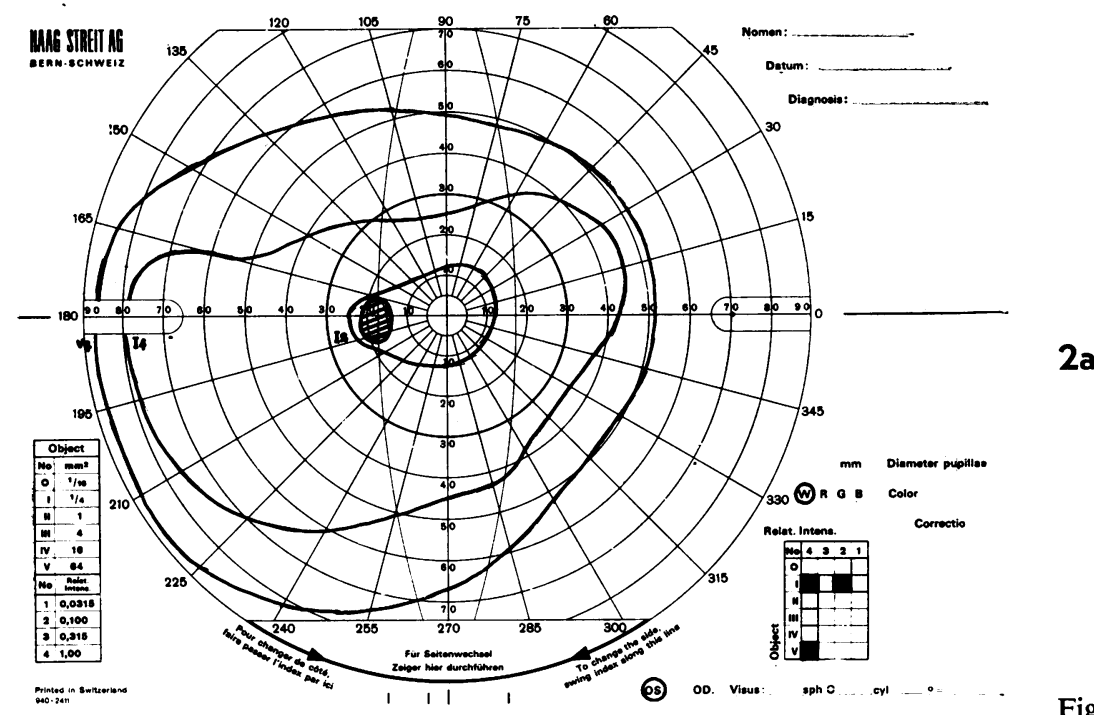

Figs. 2a, b Pretreatment visual field and 10-week post-treatment field in an argon-treated eye

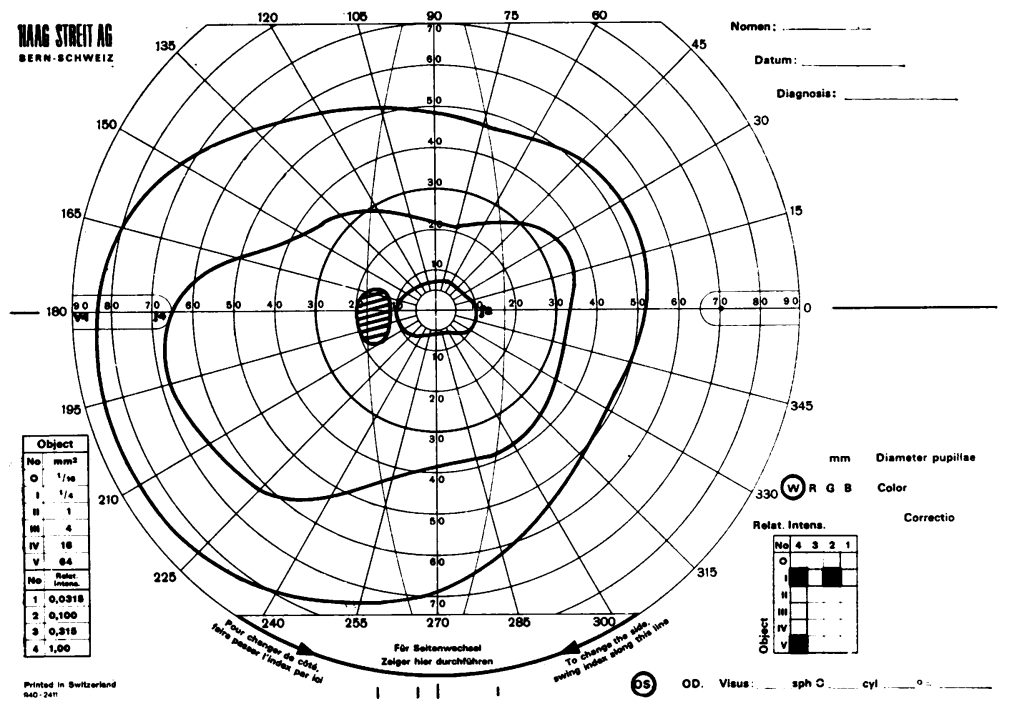

average centripetal shrinkage of 7 degrees for $I / 2$ and 3 degrees for $I / 4$ compared to 9 degrees and 5 degrees, respectively, in the argon laser-treated group (Table 2; Figs. 2 and 3).

NEOVASCULARISATION ON OPTIC DISC

Resolution of new vessels on the optic disc occurred in both groups in the study period (Figs. 4 and 5). In several eyes it was observed in both groups that the new vessels were not perfused when examined on the second day after treatment. This observation did not guarantee total regression of the disc vessels.
There was incomplete resolution of new vessels in 3 eyes belonging to the argon laser-treated group and 2 eyes in the krypton laser-treated group at the end of the study period (Table 1). Three of these eyes developed vitreous haemorrhages.

\section{SIDE EFFECTS}

Patients treated with the krypton laser more frequently complained of pain during treatment. In 3 patients in which 1 eye was treated with the krypton laser and the second eye with the argon laser a prominent subjective finding was that treatment 
Figs. 3a, b Pretreatment visual field and 10-week post-treatment

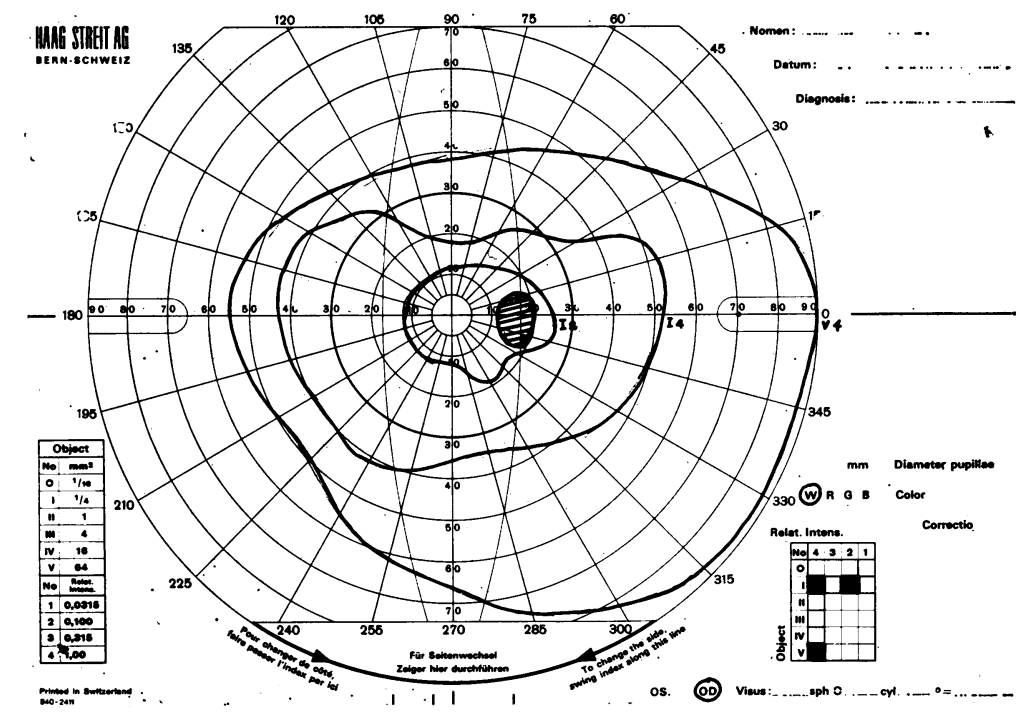
visual field in a krypton-treated eye

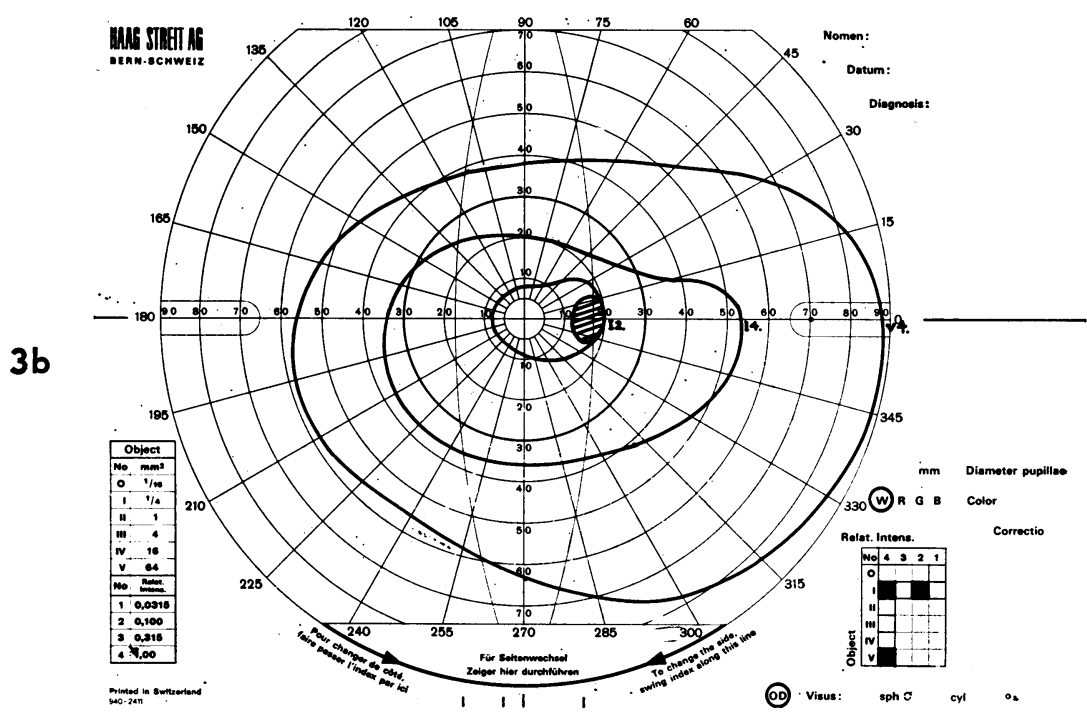

with the krypton laser was more painful. This observation was also found in subsequent patients not recruited into this study.

\section{COMPLICATIONS}

On 3 occasions with the krypton laser heavy burns resulted in small haemorrhages, almost certainly derived from the choroidal circulation and developed from the outer border of the pigment halo surrounding the burn.

The bleeding stopped within a few seconds and did not spread into the retrovitreal space. None of the patients receiving argon laser coagulation developed haemorrhages.

With the krypton laser inadvertent coagulation of blood vessels produced no spasm of the vessel or haemorrhages. With the argon laser particular attention was applied to avoiding retinal blood vessels because of the known complication of spasm and haemorrhage from inadvertent coagulation (Hamilton et al., 1976).

The average centripetal field shrinkage is smaller in the krypton laser-treated group after the 10-week period. Although the difference is small, its 

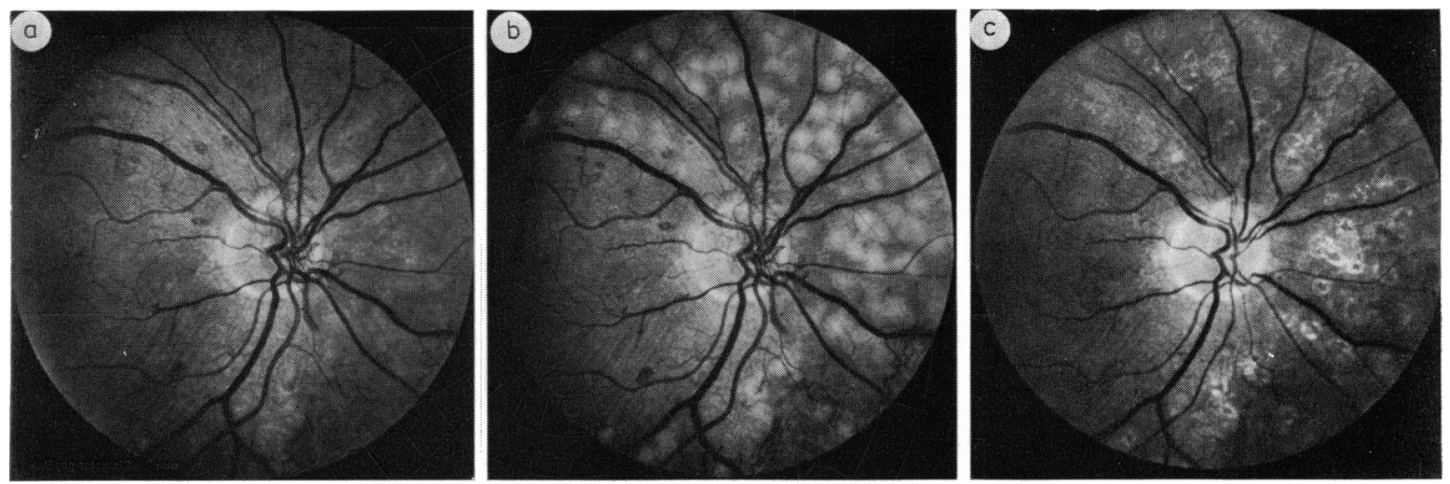

Fig. 4 The appearance of the disc new vessels (a) before treatment; (b) within a few hours of treatment; (c) 10 weeks after treatment in an argon-treated eye with complete regression of disc vessels
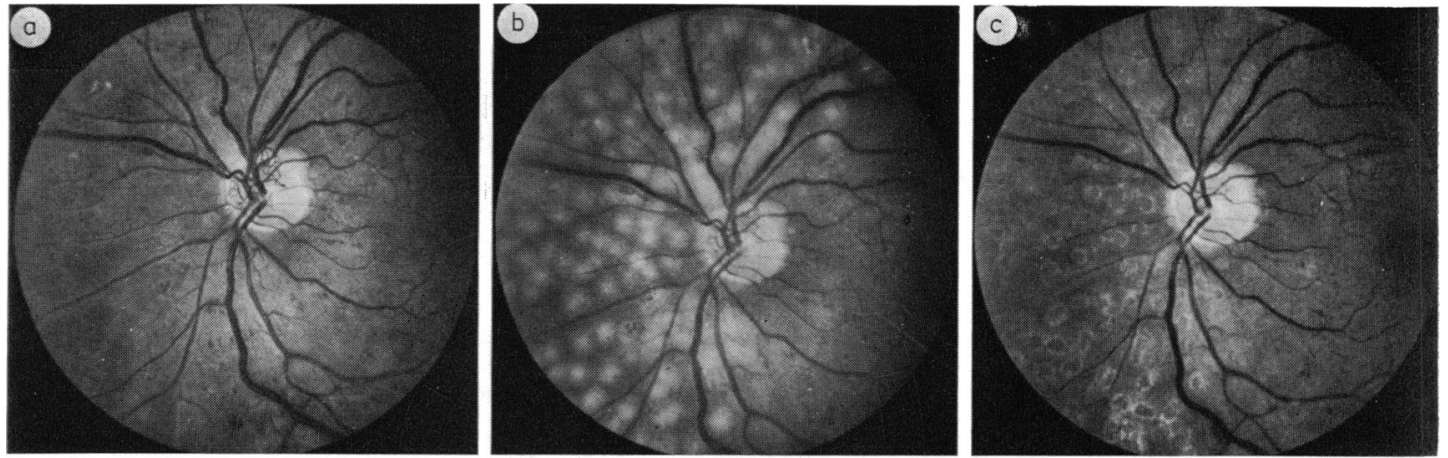

Fig. 5 (a) The appearance of the disc new vessels before treatment; (b) within a few hours of treatment; (c) 10 weeks after treatment in a krypton-treated eye with complete regression of the new vessels

significance and subsequent evolution is not yet established.

\section{Discussion}

From this limited study the krypton laser appears to be as effective as the argon laser in causing regression of optic disc neovascularisation in diabetics, and throughout this study no difference was found in the response after photocoagulation. The krypton laser wavelength theoretically has a low absorption of energy by haemoglobin, and therefore coagulation of retinal capillaries and larger retinal blood vessels does not seem to be of importance (Marshall and Bird, in preparation). Thus the success of treatment appears to depend upon the effective absorption of energy by the pigment epithelium. Because of the absence of absorption by haemoglobin the krypton laser cannot be used for the direct coagulation of new vessels. In addition, if a haemorrhage occurs during treatment it is not possible to stop the flow of blood by coagulating the bleeding area.

Of note is the high instance of annular choroidal detachment in the krypton-treated group, and this is of clinical importance because of the possibility of the precipitation of closed-angle glaucoma after treatment.

The increased incidence of annular choroidal detachment in the krypton group may be a direct result of the more penetrating krypton burn affecting the larger choroidal vessels (Marshall and Bird, in preparation).

A subjective significant finding was that treatment with the krypton laser was more painful, and it may be advisable to use a retrobulbar anaesthetic, especially when treatment is planned to be completed in 1 session. Once again this may be due to the greater penetration of the krypton burn.

The krypton laser requires further evaluation to establish the effect on retinal blood vessels and also on the optic disc. In view of the lack of absorption 
by haemoglobin it may be of use in the treatment by panretinal photocoagulation of patients with mild to moderate vitreous haemorrhages.

\section{References}

Aiello, L., Beetham, W., Marios, C. B., Chazen, B. I., and Bradley, R. F. (1968). Ruby laser photocoagulation in treatment of diabetic proliferative retinopathy; preliminary report. In Symposium on Treatment of Diabetic Retinopathy, pp. 437-463. Edited by M. Goldberg and S. Fine. US Department of Health, Education and Welfare publication no. 1890.

Cheng, H. (1976). Response of proliferative diabetic retinopathy to xenon-arc phtocoagulation. A multicentre randomised controlled trial: second interim report.
Transactions of the Ophthalmological Societies of the United Kingdom, 96, 224-227.

Diabetic Retinopathy Study Research Group (1976). Preliminary report on effects of photocoagulation therapy. American Journal of Ophthalmology, 81, 383-396.

François, J., and Cambie, E. (1971). Retinal photocoagulation (xenon-arc and lasers). Annals of Ophthalmology, 3, 1201-1208.

Hamilton, A. M., Townshed, C., Khoury, D., and Gould, E. (1976). Transactions of the Ophthalmological Societies of the United Kingdom, 96, 228-235.

Kohner, E. M., Panisset, A., Cheng, H., and Fraser, T. R. (1971). Diabetes, 20, 816-823.

L'Esperance, F. A., Jr. (1968). An ophthalmic argon laser photocoagulation system design, construction, and laboratory investigations. Transactions of the American Ophthalmological Society, 66, 827-904. 